\title{
TLC determination of flavonoids from different cultivars of Allium cepa and Allium ascalonicum
}

\author{
LORETTA POBEOCKA-OLECH ${ }^{1}$ \\ DANIEL GŁÓD ${ }^{1}$ \\ MARIA E. ŻEBROWSKA ${ }^{2}$ \\ MAŁGORZATA SZNITOWSKA ${ }^{2}$ \\ MIROSLAWA KRAUZE-BARANOWSKA ${ }^{1 *}$ \\ ${ }^{1}$ Department of Pharmacognosy with \\ Medicinal Plants Garden \\ ${ }^{2}$ Department of Pharmaceutical \\ Technology \\ Faculty of Pharmacy with Subfaculty \\ of Laboratory Medicine \\ Medical University of Gdańsk \\ 80-416 Gdańsk, Poland
}

\begin{abstract}
This study comprises the optimization and validation of a new TLC method for determination of flavonols in the bulbs of seven cultivars of onions and shallots. Separation was performed on RP-18 plates with the solvent mixture tetrahydrofuran/water/formic acid $(40+60+6, V / V / V)$ as a mobile phase. The method was evaluated for precision, linearity, LOD, LOQ, accuracy and robustness. Chromatographic analysis of the extracts revealed the presence of three main flavonols, quercetin, quercetin-4'-O-glucoside and quercetin-3,4'-O-diglucoside in the majority of analyzed cultivars. The content of flavonols in the analyzed extracts of onion bulbs varied from 123 ('Exihibition') to $1079 \mathrm{mg} \mathrm{kg}^{-1}$ fresh mass (fm) ('Hybing') in edible parts, and from 1727 ('Hyline') to $28949 \mathrm{mg} \mathrm{kg}^{-1}$ fm ('Red Baron') in outer scales. The bulbs of two shallot cultivars contained 209 ('Ambition') and $523 \mathrm{mg} \mathrm{kg}^{-1} \mathrm{fm}$ ('Matador') of flavonols in edible parts and 5426 and $8916 \mathrm{mg} \mathrm{kg}^{-1} \mathrm{fm}$ in outer scales, respectively.
\end{abstract}

Keywords: Allium cepa, Allium ascalonicum, cultivar varieties, flavonols, TLC, quantitative analysis

Onion (Allium cepa L.) and shallot (Allium ascalonicum Hort.) are among the most widely consumed vegetables (1-3). They are an important source of bioactive compounds, including flavonoids, fructo-oligosaccharides and sulfur compounds $(2,3)$. Many of these constituents have beneficial properties to human health (3). Onion bulbs extract is used for the treatment of keloids and hypertrophic scars (4). Moreover, the bulbs are active as hypocholesterolemic, hypolipidemic, anti-hypertensive, anti-diabetic, antimicrobial, antioxidant and prebiotic remedies (2).

Onion is a rich source of flavonols $(1,2)$, especially two quercetin conjugates - quercetin-4'-O-glucoside (QMG) and quercetin-3,4'-O-diglucoside (QDG) (Fig. 1) (constituting $80-85 \%$ of the total flavonoid content) $(1,5,6)$. Other flavonoids were identified as constituents of onion bulbs, namely, quercetin-3-O-diglucoside $(1,3,5,7,8)$ and isorhamnetin3,4'-O-diglucoside $(1,5,8)$.

\footnotetext{
*Correspondence; e-mail: krauze@gumed.gda.pl
} 
<smiles></smiles>

Quercetin<smiles>O=c1c(O)c(-c2ccc(OC3OC(O)C(O)C(O)C3O)c(O)c2)oc2cc(O)cc(O)c12</smiles>

Quercetin-4'-O-glucoside (spiraeoside)

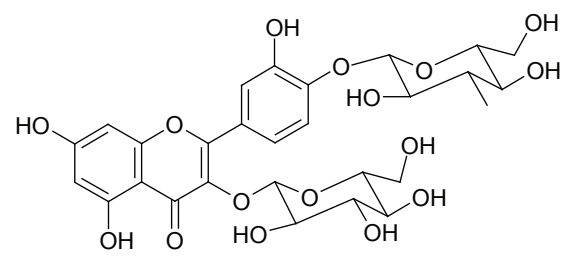

Quercetin-3,4'-di-O-glucoside

Fig. 1. The structures of analyzed compounds.

Allium cepa cultivars are classified according to skin colour, such as gold (sometimes called yellow), white or red onions $(1,9)$. Gold and red forms contain similar amounts of flavonoid compounds, which greatly exceed the levels determined for white onions $(1,9)$. According to literature data $(1,3,5-8)$ the most often investigating part of onion bulbs are inner layers (edible part), as ingredients of human diet and raw plant material for pharmaceutical industry.

Flavonoids are free radical scavengers and posses antioxidant activity (2). They can protect against cancer and reduce the risk of heart and neurodegenerative diseases (10). Previous studies showed significant differences in the levels of flavonoids in different onion and shallot cultivars $(1,3,5-8)$. It is therefore important to develop methods for the determination of flavonols for the quality control of raw plant material for pharmaceutical purposes.

The content of flavonoids in Allium species are usually determined by high performance liquid chromatography - $\operatorname{HPLC}(1,3,5-8,11)$. In our study we used thin layer chromatography (TLC), which is a simpler, cheaper and more easily available chromatographic method for different laboratories (food or pharmaceutical quality control) and is more time-effective compared to HPLC (10). 
TLC is regarded as a popular analytical technique, widely used for the analysis of plants (10). In our study the optimized and validated TLC system has been used to compare the chemical composition of bulbs from five cultivars of Allium cepa and two varieties of Allium ascalonicum originating from the Polish crop, and consequently to select of plant material with high content of flavonoids. Along, HPLC separation of nine flavonoids, some founds in the onions, was developed.

\section{EXPERIMENTAL}

\section{Chemicals}

All solvents were of analytical grade. Tetrahydrofuran and formic acid were obtained from J. T. Baker (The Netherlands), methanol from POCH (Poland) and hydrochloric acid from Merck (Germany). Water was purified using a Milli-Q water purification system (USA).

The purity of reference standards was $>95 \%$ unless specified otherwise. Quercetin was purchased from Fluka (Switzerland), quercetin-4'-O-glucoside, quercetin-3-rhamnoside, kaempferol-3-glucoside and isorhamnetin-3-glucoside (spiraeoside) were from Extrasynthèse (France). Quercetin-3-glucoside and glucose were obtained from Sigma (Germany).

Quercetin-3,4'-diglucoside, kaempferol-3,4'-diglucoside and isorhamnetin-3,4'-diglucoside were isolated from the herb Echinocystis lobata and its structure elucidation was based on UV, ${ }^{1} \mathrm{H}$ NMR, ${ }^{13} \mathrm{C}$ NMR and MS data (12). The standards were dissolved in methanol $\left(1 \mathrm{mg} \mathrm{mL}^{-1}\right)$.

\section{Plant material}

Bulbs of the following varieties of shallot (Allium ascalonicum): 'Ambition' and 'Matador', gold onion (Allium cepa): 'Armstrong', 'Exhibiton', 'Hybing', 'Hyline' and red onion 'Red Baron' were obtained from crops of the company Bejo Zaden B.V. (Konotopa, Polska) in autumn 2007 and analyzed in the same year.

\section{Sample preparation}

Three bulbs from each fresh onion and shallot variety were manually subdivided into two different parts: inner layers (the edible part) and outer scales (completely dry parts). These were cut into small cubes of an approximate size of $0.1 \mathrm{~cm}^{3}$. Plant material $(1 \mathrm{~g})$ was extracted twice with methanol $(5 \mathrm{~mL})$ at room temperature for 24 hours. The obtained extracts were evaporated to dryness under reduced pressure and then dissolved in a methanol/water $(50+50, V / V)$ mixture $(1 \mathrm{~mL})$. Three independent extract samples were prepared.

\section{Isolation and identification of compound $\mathbf{1}$}

Compound 1 was isolated from the methanolic extract of the edible part of the bulbs of Allium cepa 'Armstrong' by TLC preparative chromatography under conditions described vide infra. It was obtained as a white, crystalline substance. Compound structure was confirmed by chromatographic and spectroscopic methods (13). 
Compound 1 - quercetin-3,4'-di-O-glucoside (white, crystal substance, TLC: RP-18 TLC $h R_{\mathrm{F}}=48$. UV $\lambda_{\max }(\mathrm{MeOH}) \mathrm{nm}: 266,344 ;+\mathrm{NaOMe}: 272,378 ;+\mathrm{AlCl}_{3}: 272,346,398$; + $\mathrm{AlCl}_{3} / \mathrm{HCl}: 276,346,400 ;+\mathrm{CH}_{3} \mathrm{COONa}: 272,370 ; \mathrm{CH}_{3} \mathrm{COONa} / \mathrm{H}_{3} \mathrm{BO}_{3}: 266$, 354. Products of acid hydrolysis: quercetin (TLC, cellulose: acetic acid/hydrochloric acid/water 30+3+10, $V / V / V$ ) and glucose (TLC, silica gel: acetonitrile/water 85+15, $V / V$ ).

\section{Thin layer chromatography}

TLC was developed for 20 min on $10 \times 20 \mathrm{~cm}$ TLC RP-18 plates (Merck, Germany) with tetrahydrofuran/water/formic acid $(40+60+6, V / V / V)$ mobile phase in a horizontal DS II chamber (Chromdes, Poland) (Fig. 2).

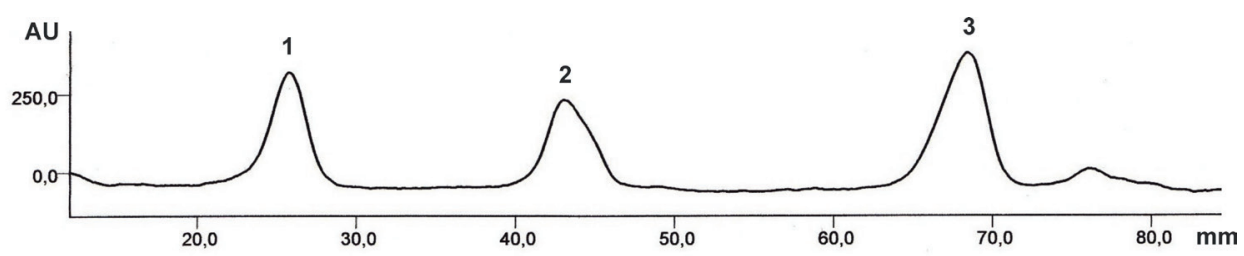

Fig. 2. Densitogram of separated flavonoids: 1 - quercetin; 2 - spiraeoside and 3 - quercetin-3,4'-diglucoside.

Standard solutions and samples were applied as $5 \mathrm{~mm}$ bands, $10 \mathrm{~mm}$ from the bottom edge of the plates, by means of a Desaga AS-30 sample applicator (Desaga, Germany). Plates were developed to a distance of $8 \mathrm{~cm}$ at room temperature. The calibration function was obtained from the stock solution of quercetin in methanol $\left(2.5 \mathrm{mg} \mathrm{mL}^{-1}\right)$, which was diluted to seven different working solutions $\left(0.1,0.15,0.25,0.35,0.45,0.55,0.6 \mathrm{mg} \mathrm{mL}^{-1}\right)$. The volume of the spot applied was $2-20 \mu \mathrm{L}$. The calibration curve was constructed by plotting the peak areas against the concentration of each standard solution $(R=0.9992)$. Densitograms were obtained at $366 \mathrm{~nm}$ with the aid of a densitometer Desaga CD 60 (Germany). For qualitative analysis, linear scans were obtained with a slit of $0.02 \times 2 \mathrm{~mm}$, and for quantitative determination, chromatograms were scanned with a $7 \mathrm{~mm}$ wide meander with a $0.4 \times 0.4-\mathrm{mm}$ slit. Contents of flavonols in onions and shallots under study were expressed as quercetin equivalents $(\mathrm{QE})$ on the fresh mass basis.

\section{Preliminary validation}

Validation parameters were estimated according to FDA. They included precision, linearity, detection $(L O D)$ and quantification $(L O Q)$ limits, accuracy and robustness (Table I). All precision data are presented in Table I. Instrument precision was checked by repeated scanning of the same spot of quercetin (700 ng) seven times at $\lambda=366 \mathrm{~nm}$. Repeatability of the method was determined by analyzing standard solution of quercetin (700 ng per spot) after application on the TLC plate $(n=7)$. Intra-day precision was determined by analyzing seven spots (700 ng) of quercetin per plate on three TLC plates. Inter-day precision was studied by analyzing seven spots $(700 \mathrm{ng})$ of standard solutions per plate on three consecutive days. 
L. Pobłocka-Olech et al.: TLC determination of flavonoids from different cultivars of Allium cepa and Allium ascalonicum, Acta Pharm. 66 (2016) 543-554.

Table I. Some analytical performance data for determination of quercetin by TLC

\begin{tabular}{lc}
\hline Analytical performance data & \\
\hline Regression equation & $y=1.57 x+17.73$ \\
Correlation coeficient $(R)$ & 0.9992 \\
$L O D\left(\mathrm{mg} \mathrm{mL}^{-1}\right)$ & 0.038 \\
LOQ $\left(\mathrm{mg} \mathrm{mL}^{-1}\right)$ & 0.125 \\
Instrumental precision RSD (\%) ${ }^{\mathrm{a}}$ & 0.9 \\
Repeatability RSD (\%) & 1.5 \\
Inter-day assays RSD (\%) & 3.5 \\
Intra-day assays RSD (\%) & 3.9 \\
Recovery (\%) & $103.5-104.9$ \\
\hline
\end{tabular}

${ }^{\mathrm{a}} n=6,{ }^{\mathrm{b}} n=3$

Table II. Robustness testing of TLC method

\begin{tabular}{lcc}
\hline Factor & Level of changes & RSD $(\%)$ \\
\hline & $39+61+6$ & 1.8 \\
Mobile phase composition $(V / V / V)(\mathrm{mL})$ & $40+60+6$ & 1.6 \\
& $41+59+6$ & 1.8 \\
\hline \multirow{2}{*}{ Detection wavelength $(\mathrm{nm})$} & 370 & 0.9 \\
& 366 & 0.7 \\
\hline & 362 & 0.9 \\
\hline
\end{tabular}

The accuracy of the method was established by performing a recovery study by the standard addition method. The quercetin standard was added to the samples of onion bulbs (A. cepa 'Armstrong') at three levels (80, 100 and $120 \%$ ) and each was extracted and analyzed as described in the assay (Table I).

Robustness of the method was tested by determining small variations in the mobile phase composition, wavelength and development distance. It was assessed for $700 \mathrm{ng}$ quercetin standard per band (Table II).

\section{High performance liquid chromatography}

The HPLC system comprised an L-7100 pump (Merck-Hitachi, Germany-Japan) and a detector UV-VIS L-7420 (Merck-Hitachi). Solvent A was acetonitrile/water/formic acid 


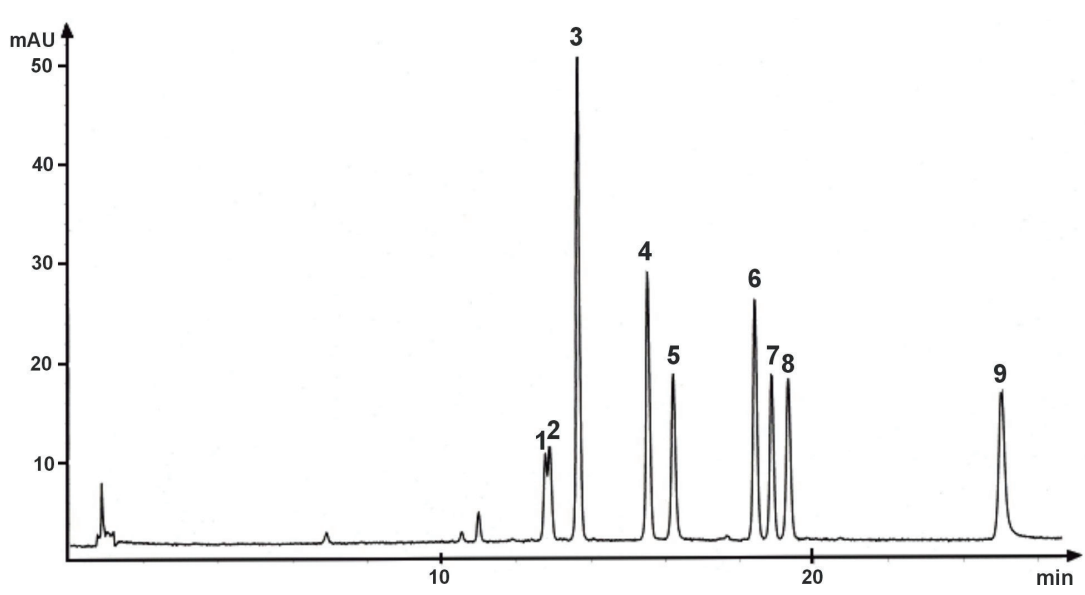

Fig. 3. HPLC chromatogram of standard mixture: 1 - quercetin-3,4'-diglucoside; 2 - kaempferol-3,4'diglucoside; 3 -isorhamnetin-3,4'-diglucoside; 4 - quercetin-3-rhamnoside; 5 - quercetin-3-glucoside; 6 - kaempferol-3-glucoside; 7 - isorhamnetin-3-glucoside; 8 - spiraeoside; 9 - quercetin.

$(50+50+0.1, V / V / V)$ and solvent B was water/formic acid (100+0.1, V/V). Samples were eluted using the gradient program from 10 to $100 \%$ of $A$ in the $A+B$ mixture at a flow rate of $1 \mathrm{~mL}$ $\mathrm{min}^{-1}$, on a Discovery HS C18 column $(75 \times 4.6 \mathrm{~mm}, 3 \mu \mathrm{m}$, Supelco, USA). Column temperature was $25^{\circ} \mathrm{C}$, run time was $26 \mathrm{~min}$ and detection wavelength was $366 \mathrm{~nm}$ (Fig. 3).

\section{RESULTS AND DISCUSSION}

\section{Optimization of TLC chromatographic separation}

Literature data (14) concerning the TLC analysis of flavonoids in onion bulbs comprised determination of quercetin after acid hydrolysis of the extracts and separation on TLC silica gel 60 plates using of ethyl acetate/formic acid/bidistilled water $85+10+15(V / V / V)$ as mobile phase. In our study, optimization of TLC separation was performed to obtain optimal conditions for the resolution of the standard mixture - quercetin, spiraeoside and quercetin 3,4'-di-O-glucoside (Fig. 1) employing different types of adsorbents, namely, cellulose, silica gel and modified silica gel - RP-18.

The mobile phases used in normal phase systems were mixtures with ethyl acetate, methanol, water, 1,2-dichloroethanol, butanol, chloroform, acetone, acetic or hydrochloric or formic acid, in different combinations and proportions. In reversed phase systems, the mobile phases used were mixtures of water and different organic modifiers such as tetrahydrofuran, acetonitrile, methanol or isopropanol with the addition of formic acid. Good resolution of analyzed flavonols was achieved on RP-18 and the best was obtained with a tetrahydrofuran-water-formic acid $(40+60+6, V / V / V)$ mixture as the mobile phase. Densitograms showed good separation of flavonols with symmetric peaks (Fig. 2, Table III).

There were three dominant peaks in the majority of chromatograms (Figs. 4 and 5): the first identified as quercetin and the second as quercetin-4'-O-glucoside - spiraeoside 
L. Pobłocka-Olech et al.: TLC determination of flavonoids from different cultivars of Allium cepa and Allium ascalonicum, Acta Pharm. 66 (2016) 543-554.

Table III. Some data of separated flavonoids in the extract from bulbs of onions and shallots

\begin{tabular}{lcc}
\hline \multirow{2}{*}{ Compound } & \multicolumn{2}{c}{ Chromatographic parameter } \\
\cline { 2 - 3 } & $\mathrm{TLC} h R_{\mathrm{F}}$ & $\mathrm{HPLC}\left(t_{\mathrm{R}}\right.$, $\left.\min \right)$ \\
\hline Quercetin & 17.6 & 25.1 \\
Quercetin-4'-O-glucoside & 30.5 & 19.5 \\
Quercetin-3-O-rhamnoside & 48.2 & 15.6 \\
Quercetin-3- O-glucoside & & 16.3 \\
Kaempferol-3- O-glucoside & & 18.5 \\
Isorhamnetin-3- O-glucoside & & 19.0 \\
Quercetin-3,4'- O-diglucoside & & 12.8 \\
Kaempferol-3,4'- O-diglucoside & & 13.0 \\
Isorhamnetin-3,4'- O-diglucoside & & 13.8 \\
\hline
\end{tabular}

$h R_{\mathrm{F}}=R_{\mathrm{F}} \times 100$

(Fig. 1). The third compound was isolated from the methanolic extract of A. cepa 'Armstrong' by preparative thin layer chromatography (TLC) under the chromatographic conditions described above. On the basis of UV spectra and TLC analysis of the products of acid hydrolysis, the structure of the compound was determined as quercetin-3,4'-O-diglucoside (Fig. 1). Spiraeoside was identified in all analyzed extracts. Quercetin was not found in the inner layers from shallots and the 'Hyline' onion variety, whereas quercetin-3,4'-Odiglucoside was not identified in the outer scales of all onions and in the 'Matador' shallot variety (Figs. 4 and 5).

\section{HPLC separation}

To control the efficiency of TLC resolution, simultaneously HPLC separation of the mixture of nine flavonols, including some identified in onions, was developed (Table III). The separated standard mixture consisted of the compounds previously described in onion bulbs: quercetin $(1,7,8)$, quercetin-3-O-glucoside $(1,3,5,7,8)$, quercetin-4'-O-glucoside (spiraeoside) $(1,3,5,7,8)$, quercetin-3,4'-O-diglucoside $(1,3,5,7,8)$, isorhamnetin-3,4'-Odiglucoside $(1,5,8)$. Other flavonols used in the standard mixture, kaempferol-3,4'-O-diglucoside, quercetin-3-O-rhamnoside, isorhamnetin-3-O-glucoside, kaempferol-3-O-glucoside were introduced as possessing similar structures to those earlier identified in onions (Fig. 3).

In contrast to TLC, HPLC analysis revealed the presence of trace amounts of quercetin-3,4'-O-diglucoside in the extracts from outer scales of Allium cepa 'Armstrong' and 'Hybing' (Fig. 5).

\section{Preliminary validation of TLC method}

Some analytical performances are displayed in Table I. 
L. Pobłocka-Olech et al.: TLC determination of flavonoids from different cultivars of Allium cepa and Allium ascalonicum, Acta Pharm. 66 (2016) 543-554.
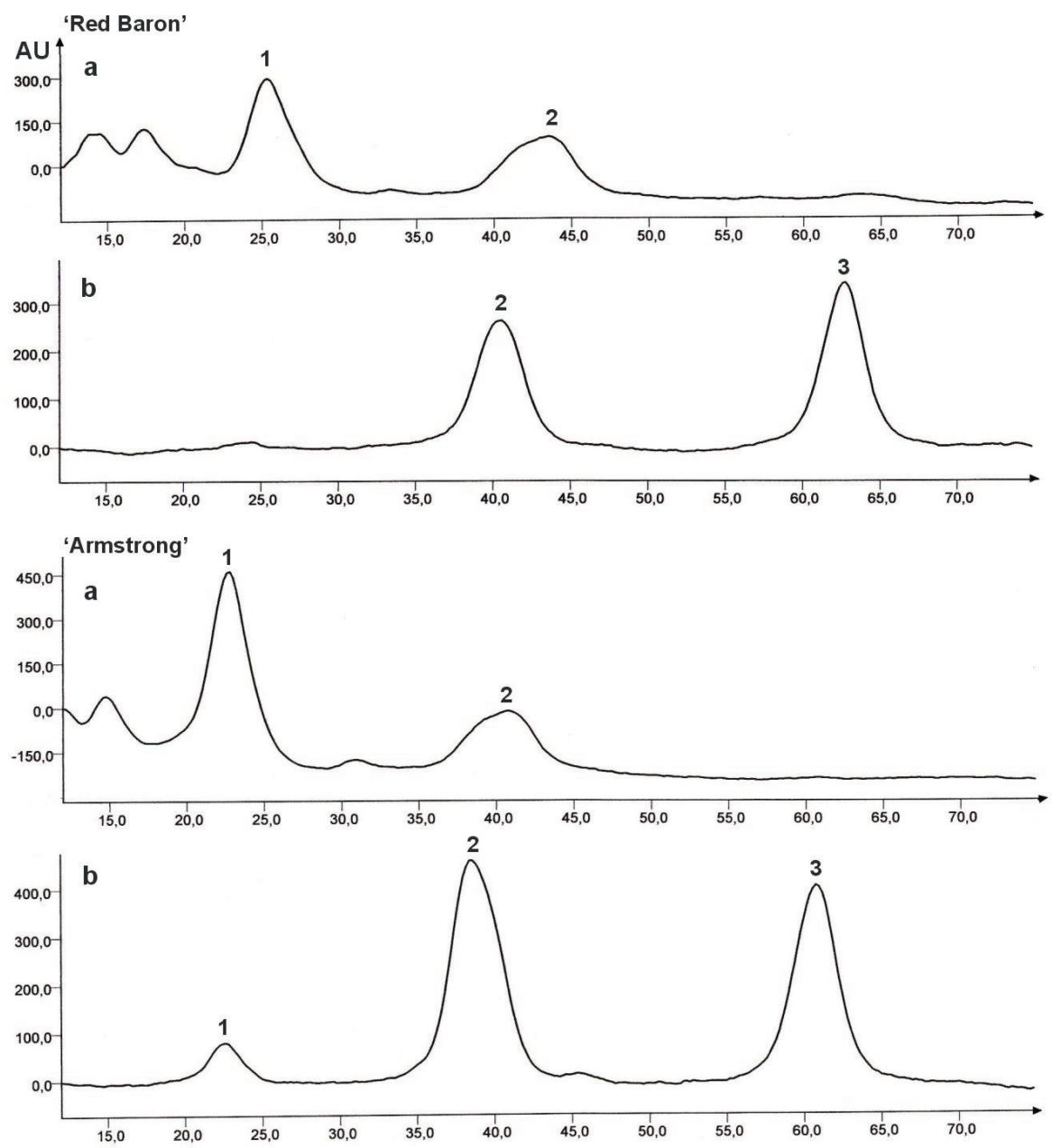

'Exibition'
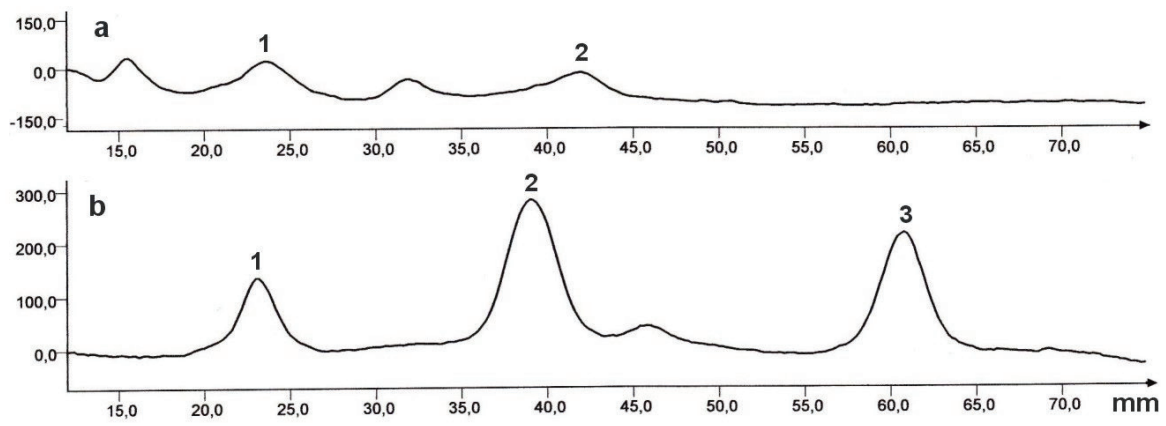

Fig. 4. Densitograms of the methanolic extracts of: a) outer scales and b) inner layers from bulbs of Allium cepa varieties: 1 - quercetin; 2 - spiraeoside; 3 -quercetin-3,4'-diglucoside. 
L. Pobłocka-Olech et al.: TLC determination of flavonoids from different cultivars of Allium cepa and Allium ascalonicum, Acta Pharm. 66 (2016) 543-554.
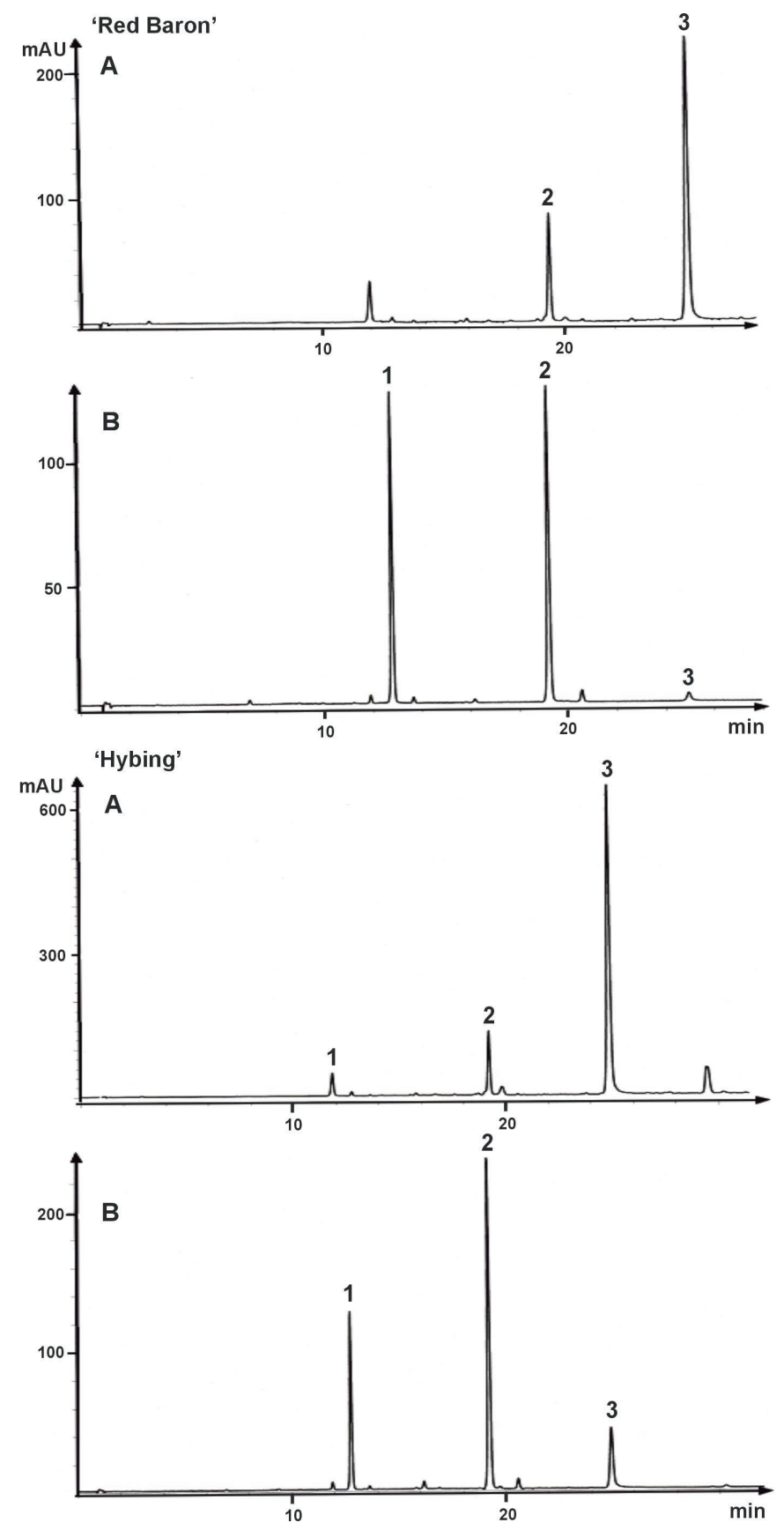

Fig. 5. HPLC chromatograms of the methanolic extracts of: a) outer scales and b) inner layers from bulbs of Allium cepa varieties: 1 - quercetin-3,4'-diglucoside; 2 - spireoside; 3 - quercetin. 


\section{Flavonoids in onions and shallots}

Big differences in the level of flavonoids in onions and shallots were found (Tables IV and V). The same tables display the contents of quercetin and spiraeoside, they were markedly higher in the outer scales than in inner layers.

Expressed on the fresh mass basis, the content of flavonols in the inner layers (edible part) of onions varied from 11 ('Red Baron') to $115 \mathrm{mg} \mathrm{kg}^{-1}$ ('Hybing') for quercetin, 54 ('Exibition') to $534 \mathrm{mg} \mathrm{kg}^{-1}$ ('Hybing') for QMG, and 45 ('Exibition') to $430 \mathrm{mg} \mathrm{kg}^{-1}$ ('Hybing') for QDG (Table IV). High contents of quercetin, ranging from 2384 ('Exibition') to $14589 \mathrm{mg} \mathrm{kg}^{-1}$ ('Red Baron'), characterized the outer scales of onions. However, similar amounts of spiraeoside, from 3086 ('Exibition') to $14360 \mathrm{mg} \mathrm{kg}^{-1}$ ('Red Baron'), were found. The obtained results are in accord with the earlier studies on flavonoid content in onions $(1,5-8,16)$.

The chemical composition of two shallot varieties (Allium ascalonicum), 'Ambition' and 'Matador', and three onions (Allium cepa), 'Armstrong', 'Hybing' and 'Hyline', was analyzed for the first time.

In accord with the work of Beesk et al. (6), two varieties, 'Exibition' and 'Red Baron', had lower contents of analyzed flavonols (Tables IV and V). However, the quercetin content in Allium сера 'Red Baron' outer scales and the quercetin content in edible parts of both onions were similar. In contrast to our results, the aforementioned authors found high levels of quercetin-3,4'-O-diglucoside in outer scales of both cultivars, namely $4800 \mathrm{mg} \mathrm{kg}^{-1}$ $\mathrm{fm}$ for 'Exibition' and $13000 \mathrm{mg} \mathrm{kg}^{-1} \mathrm{fm}$ for 'Red Baron'. These differences could be explained by the fact that onions analyzed by Beesk and co-workers (6) were cultivated under controlled conditions in a greenhouse.

In our study, the highest flavonol content was found in edible parts of gold onion „Hybing” (1079 $\mathrm{mg} \mathrm{kg}^{-1}$ ) and in outer scales of 'Armstrong' (18780 $\left.\mathrm{mg} \mathrm{kg}^{-1}\right)$. However, in

Table IV. Flavonoid content of edible part of onion and shallot (inner layers) ${ }^{a}$

\begin{tabular}{lccc}
\hline Variety & Quercetin & Spiraeoside & Quercetin-3,4'-diglucoside \\
\hline Gold onion: & & & \\
\hline Armstrong & $17 \pm 1$ & $132 \pm 47$ & $109 \pm 19$ \\
Exhibition & $24 \pm 4$ & $54 \pm 3$ & $45 \pm 3$ \\
Hybing & $115 \pm 24$ & $534 \pm 42$ & $430 \pm 35$ \\
Hyline & - & $510 \pm 20$ & $62 \pm 4$ \\
Red onion: & - & & $168 \pm 46$ \\
Red Baron & $11 \pm 1$ & $434 \pm 18$ & \\
Shallot: & - & & $139 \pm 36$ \\
Ambition & - & $357 \pm 23$ & $166 \pm 17$ \\
Matador & & & \\
\hline
\end{tabular}

${ }^{a}$ Expressed in $\mathrm{mg} \mathrm{QE} \mathrm{kg}^{-1} \mathrm{fm} \pm \mathrm{RSD}(\%), n=3$. 
L. Pobłocka-Olech et al.: TLC determination of flavonoids from different cultivars of Allium cepa and Allium ascalonicum, Acta Pharm. 66 (2016) 543-554.

Table V. Flavonoid content of outer scales of onion and shallot ${ }^{a}$

\begin{tabular}{lccc}
\hline Variety of & Quercetin & Spiraeoside & Quercetin 3,4'-diglucoside \\
\hline Gold onion: & & & \\
\hline Armstrong & $12163 \pm 161$ & $6617 \pm 385$ & - \\
Exhibition & $2384 \pm 329$ & $3086 \pm 242$ & - \\
Hybing & $10677 \pm 396$ & $7184 \pm 255$ & - \\
Hyline & $8606 \pm 366$ & $8669 \pm 312$ & - \\
Red onion: & & & - \\
Red Baron & $14589 \pm 382$ & $14360 \pm 255$ & - \\
Shallot: & & & - \\
Ambition & $5236 \pm 428$ & $2896 \pm 179$ & \\
Matador & $2258 \pm 258$ & $3168 \pm 227$ & \\
\hline
\end{tabular}

a Expressed in $\mathrm{mg} \mathrm{QE} \mathrm{kg}^{-1} \mathrm{fm} \pm \mathrm{RSD}(\%), n=3$.

the outer scales of the analyzed red form of onion, 'Red Baron', the level of flavonoids was much higher: $28949 \mathrm{mg} \mathrm{kg}^{-1}$ (Tables IV and V). The values for edible parts of 'Hybing' were close to the flavonol content determined for other onions from Poland (7). However, the variety "Exibition' of Allium cepa was most deficient in analyzed compounds, with the levels about nine times lower than in the richest one (Table IV).

Two analyzed varieties of shallot, 'Ambition' and 'Matador', had very differerent contents of spiraeoside in edible parts (70 and $357 \mathrm{mg} \mathrm{kg}^{-1}$, respectively) and similar levels of quercetin-3,4'-O-diglucoside (139 and $166 \mathrm{mg} \mathrm{kg}^{-1}$ ) (Table IV). These contents were lower than those reported in the literature (1). In the present study, flavonoid concentrations in the outer scales of Allium ascalonicum bulbs were determined for the first time (Table V).

\section{CONCLUSIONS}

We developed and validated a simple, fast and cheap TLC method for quality control of onion and shallot. It was applied in the analysis of flavonoids in the methanolic extracts of inner layers (edible part) and in outer scales from five varieties of onion and two varieties of shallot.

The observed differences in flavonol content point to the importance of quantitative control of flavonoids, especially in the quality control of onions used in pharmaceutical industry. This information could be also useful for food industry, using different parts of onion as a source of bioactive quercetin for colouring and enhancement of the physiological potential of functional food. 


\section{REFERENCES}

1. P. Bonaccorsi, C. Carsti, C. Gargiulli and U. Leuzzi, Flavonol glucosides in Allium species: A comparative study by means of HPLC-DAD-ESI-MS-MS, Food Chem. 107 (2008) 1668-1673; DOI: 10.1016/j.foodchem.2007.09.053.

2. V. Lanzotti, The analysis of onion and garlic, J. Chromatogr. A 1112 (2006) 3-22; DOI: 10.1016/j. chroma.2005.12.016.

3. T. H. Soininen, N. Jukarainen, R. Julkunen-Tiitto, R. Karjalainen and J. J. Vepsäläinen, The combined use of constrained total-line-shape ${ }^{1} \mathrm{H}$ NMR and LC-MS/MS for quantitative of bioactive components in yellow onion, J. Food Comp. Anal. 25 (2012) 208-214; DOI: 10.1016/j.jfca.2011.09.001.

4. M. Pikuła, M. E. Żebrowska, L. Pobłocka-Olech, M. Krauze-Baranowska, M. Sznitowska and P. Trzonkowski, Effect of enoxaparin and onion extract on human skin fibroblast cell line - Therapeutic implications for treatment of keloids, Pharm. Biol. 52 (2014) 262-267; DOI: 10.3109/13880209.2013.826246.

5. P. Bonaccorsi, C. Caristi, C. Gargiulli and U. Leuzzi, Flavonol glucoside profile of southern Italian red onion (Allium cepa L.), J. Agr. Food Chem. 53 (2005) 2733-2740; DOI: 10.1021/jf048152r.

6. N. Beesk, H. Perner, D. Schwarz, E. George, L. W. Kroh and S. Rohn, Distribution of quercetin-3,4'$\mathrm{O}$-diglucoside, quercetin-4'-O-monoglucoside, and quercetin in different parts of the onion bulb (Allium cepa L.) influenced by genotype, Food Chem. 122 (2010) 566-571; DOI: 10.1016/j.foodchem.2010.03.011.

7. K. Grzelak, J. Milala, B. Król, F. Adamicki and E. Badełek, Content of quercetin glycosides and fructooligosaccharides in onion stored in a cold room, Eur. Food Res. Technol. 228 (2009) 1001-1007; DOI: 10.1007/s00217-009-1018-z.

8. I. M. Vågen and R. Slimestad, Amount of characteristic compounds in 15 cultivars of onion (Allium cepa L.) in controlled field trials, J. Sci. Food Agr. 88 (2008) 404-411; DOI: 10.1002/jsfa.3100.

9. M. Marotti and R. Piccaglia, Characterization of flavonoids in different cultivars of onion (Allium cepa L.), J. Food Sci. 67 (2002) 1229-1232; DOI: 10.1111/j.1365-2621.2002.tb09482.x.

10. C. Cimpoiu, Analysis of some natural antioxidants by thin-layer chromatography and high performance thin-layer chromatography, J. Liq. Chromatogr. Relat. Technol. 29 (2006) 1125-1142; DOI: 10.1080/10826070600574911.

11. T. Vanitha, H. Sumathy, J. Sangeetha, B. Devaki and K. Vijayalakshmi, Phytochemical analysis of Allium ascalonicum, Biomedicine 29 (2009) 22-25.

12. M. Krauze-Baranowska and W. Cisowski,._Flavonoids from Echinocystis lobata and E. wrightii, Pol. J. Chem. 70 (1996) 430-436.

13. K. R. Markham, Techniques of Flavonoids Identification, Academic Press, London 1982.

14. I. Vovk, B. Simonovska, S. Andrenšek, T. Yrjönen, P. Vuorela and H. Vuorela, Rotation planar extraction and medium-pressure solid-liquid extraction of onion (Allium cepa), J. Planar Chromatogr. 16 (2003) 66-70; DOI: 10.1556/JPC.16.2003.1.14

15. L. Gennaro, Ch. Leonardi, F. Esposito, M. Salucci, G. Maiani, G. Quaglia and V. Fogliano, Flavonoid and carbohydrate contents in Tropea red onions: Effects of homelike peeling and storage, J. Agr. Food Chem. 50 (2002) 1904-1910; DOI: 10.1021/jf011102r. 